\title{
REPRESENTAÇÕES E PRÁTICAS DE CUIDADO COM A FERIDA CRÔNICA DE MEMBRO INFERIOR: UMA PERSPECTIVA ANTROPOLÓGICA
}

\author{
Lucas Pereira de Meloํ, Nello Pereira da Silva², Kelly Cristina Lopes da Silva ${ }^{3}$, Marco Philipe Teles Reis Ponte ${ }^{4}$, Dulce Maria Rosa Gualda
}

\begin{abstract}
RESUMO: O objetivo deste estudo foi interpretar as manifestações e representações culturais de cuidado de usuários portadores de ferida crônica de membro inferior. Trata-se de pesquisa clínico-qualitativa realizada de fevereiro a março de 2010. Utilizou-se a entrevista individual semiestruturada a 8 usuários de serviço ambulatorial; as entrevistas foram analisadas por meio da técnica de análise de conteúdo. Do estudo emergiram as categorias temáticas: Não vejo a hora de sarar para trabalhar! - impacto da ferida na vida cotidiana; O povo vai me ensinando as coisas e eu faço! - práticas de cuidado com a ferida crônica; É o nervoso! - um modelo explicativo. Pode-se considerar que os diversos problemas de saúde que se tornam visíveis na materialidade do corpo físico são, igualmente, permeados por questões simbólicas que se inscrevem no plano da vida cotidiana dos seus portadores, reafirmando o caráter social do processo saúde-doença.

PALAVRAS-CHAVE: Ferimentos e lesões; Antropologia cultural; Enfermagem; Medicina tradicional.
\end{abstract}

\section{REPRESENTATIONS AND CARE PRACTICES WITH A CHRONIC WOUND OF THE INFERIOR MEMBER: AN ANTHROPOLOGICAL PERSPECTIVE}

\begin{abstract}
The objective of this study was to interpret the cultural manifestations and representations of care of health-service users with chronic wounds to inferior members. The research is clinic-qualitative and was carried out in February and March 2010. Individual semi-structured interviews were carried out with 8 users of the ambulatory service; the interviews were analysed with the technique of content analysis. The following thematic categories emerged from the study: I can't wait to get better to get back to work! - impact of the wound on daily life; Folk tell me stuff and I try it! practices of care with a chronic wound; It's being irritable! - an explicative model. One may consider that the diverse health problems which become visible in the materiality of the physical body are, equally, permeated with symbolical questions which write themselves across the daily life of their carriers, reaffirming the social character of the health-illness process. KEYWORDS: Wounds and lesions; Cultural anthropology; Nursing; Traditional medicine.
\end{abstract}

\section{REPRESENTACIONES Y PRÁCTICAS DE CUIDADO CON LA HERIDA CRÓNICA DE MIEMBRO INFERIOR: UNA PERSPECTIVA ANTROPOLÓGICA}

RESUMEN: El objetivo de este estudio fue interpretar las manifestaciones y representaciones culturales de cuidado de usuarios portadores de herida crónica de miembro inferior. Se trata de investigación clínico cualitativa realizada de febrero a marzo de 2010. Se utilizó la entrevista individual semiestructurada a 8 usuarios de servicio ambulatorial; las entrevistas fueron analizadas por medio de la técnica de análisis de contenido. Del estudio, surgieron las categorías temáticas: No veo la hora de estar sano para trabajar! - impacto de la herida en la vida cotidiana; La gente me enseña las cosas y yo las hago! - prácticas de cuidado con a herida crónica; Él es nervioso! - un modelo explicativo. Es posible considerar que los diversos problemas de salud que se vuelven visibles en la materialidad del cuerpo físico son, igualmente, permeados por cuestiones simbólicas que se inscriben en el plan de la vida cotidiana de sus portadores, reafirmando el carácter social del proceso salud-enfermedad.

PALABRAS CLAVE: Heridas y lesiones; Antropología cultural; Enfermería; Medicina tradicional.

${ }^{1}$ Enfermeiro. Doutorando no Programa Interunidades de Doutoramento em Enfermagem dos campi São Paulo e Ribeirão preto da Universidade de São Paulo. Bolsista CNPq. Professor da Faculdade Anhanguera de Campinas, Unidade 3 - FAC 3.

${ }^{2}$ Enfermeiro do Centro Cirúrgico do Hospital Centro Médico de Campinas.

${ }^{3}$ Enfermeira. Coordenadora de Enfermagem do Centro Cirúrgico e Central de Material e Esterilização do Hospital e Maternidade Galileo.

${ }^{4}$ Acadêmico de Medicina pela Universidade Federal do Piauí. Bolsista de Iniciação Científica. Membro do Núcleo de Pesquisas em Plantas Medicinais.

${ }^{5}$ Obstetriz. Doutora em Enfermagem. Professora do Departamento de Enfermagem Materno-infantil e Psiquiátrica da Universidade de São Paulo.

Autor correspondente:

Lucas Pereira de Melo

Universidade de São Paulo

Endereço: Rua Luiz Vicentin Sobrinho, 553 - 13084-030 - Campinas-SP-Brasil

Email:1pmelo@usp.br

Recebido: 08/01/11

Aprovado: $30 / 03 / 11$ 


\section{INTRODUÇÃO}

Com a transição do perfil epidemiológico mundial nos últimos anos, a emergência das doenças crônicas tem assumido um lugar importante na agenda das políticas de saúde do Brasil e do mundo ${ }^{(1)}$. Neste contexto, as feridas crônicas de membro inferior (FCMI), ou úlceras de perna, merecem especial atenção, uma vez que tendem a estar associadas a doenças crônicas diversas.

As FCMI, comumente localizadas na porção distal e maleolar da perna e com presença de exudadato, caracterizam-se por suas formas e tamanhos irregulares, são superficiais inicialmente, evoluindo, ou não, com profundidade. Geralmente estão associadas a doenças como diabetes mellitus, hipertensão arterial sistêmica, insuficiência arterial, artrite reumatóide, neuropatia, osteomielite crônica, vasculites, linfedema, traumas diversos, anemia falciforme, tumores cutâneos, doenças infecciosas crônicas, carcinomas basocelulares, tuberculose e leishmaniose ${ }^{(2)}$.

$\mathrm{Na}$ formação profissional e nos serviços de assistência à saúde evidencia-se a predominância do enfoque biomédico no cuidado ao usuário com lesão de pele, privilegiando-se as manifestações biológicas e alterações clínicas que interferem no processo de reparo tecidual e no tratamento instituído. Além disso, destaca-se a existência de um universo de práticas de cuidados permeadas por orientações profissionais e conselhos de amigos, vizinhos, familiares, benzedeiras, curandeiros, raizeiros e outros ${ }^{(3)}$.

Diante da complexidade que envolve os fenômenos concernentes ao processo de adoecimento e vivência com a FCMI, há a necessidade de práticas de cuidado com abordagens que possibilitem superar a dimensão biológico-visível. Coloca-se também a importância de programas de Educação em Serviço sobre tratamento de feridas ${ }^{(4)}$, no entanto, é premente que estes programas transcendam os conhecimentos sobre os aspectos físicos e psíquicos das lesões de pele e de seu tratamento. Neste sentido, tornam-se necessárias atitudes do profissional de saúde que compreendam as variadas dimensões que compõem o processo de viver e ser saudável: biológica, social, cultural, subjetiva.

Os indivíduos adoecidos apresentam comportamentos e pensamentos singulares em relação à experiência da doença, assim como noções particulares sobre saúde e terapêutica. Tais particularidades não advêm das diferenças biológicas, mas, sim, das diferenças socioculturais. Portanto, parte-se do pressuposto de que é a cultura que determina essas particularidades. Igualmente, sustenta-se que as questões inerentes à saúde e à doença devem ser pensadas a partir dos contextos socioculturais específicos nos quais as mesmas ocorrem $^{(5)}$.

Nesse sentido, este estudo problematizou, desde uma perspectiva antropológica, algumas dimensões geralmente secundarizadas pela Biomedicina Cartesiana: as manifestações e representações culturais de cuidado vivenciadas por portadores de FCMI. Entendese representação como um tipo de saber, socialmente negociado, contido no senso comum e na dimensão cotidiana, que permite ao indivíduo uma visão de mundo e o orienta nos projetos de ação e nas estratégias que desenvolve em seu meio social. São conhecimentos culturalmente carregados, que adquirem sentido e significado plenos apenas se for considerando o contexto em que se manifestam ${ }^{(6)}$.

Esta perspectiva teórica aborda o viver humano como um processo multifacetado e complexo, que se constroi historicamente, de forma individual e coletiva, em âmbito local e global, por meio dos recursos sociais, culturais, políticos, econômicos, ecológicos, geográficos, tecnológicos, educacionais, entre outros ${ }^{(7)}$. $\mathrm{Nas}$ sociedades complexas, as percepções de saúde e de doença estão presentes nos diversos imaginários sociais, configurando um cenário plural de assistência à saúde, baseado no modo próprio de cada indivíduo explicar, diagnosticar e tratar os problemas reais ou potenciais de saúde ${ }^{(8)}$. Pode-se constatar, na verdade, uma coexistência de sistemas de cuidado à saúde que variam de fundamentação e que podem originar-se de diferentes culturas ${ }^{(9)}$.

Acredita-se que a vivência do processo saúdedoença pelos indivíduos de cada sociedade está enraizada nos valores, crenças, práticas, representações, imaginários, significados, experiências individuais e coletivas, reafirmando o caráter sociocultural dos fenômenos que o compõe, além, é claro, de fatores psicobiológicos nele envolvidos ${ }^{(10)}$. Deste modo, a saúde e a doença são tidas como não-neutras e culturais, não somente biológica ou psicológica, mas também uma realidade social envolvida por aspectos simbólicos.

O estudo dessas relações é essencial à Enfermagem, pois possibilita a compreensão da maneira como os indivíduos as percebem, mas também como os enfermeiros se inserem e interagem nesse contexto marcado pela diversidade cultural, possibilitando um novo enfoque ao cuidado de enfermagem. Sendo assim, objetivou-se neste estudo interpretar as manifestações 
e representações culturais de cuidado de usuários portadores de FCMI em um serviço público de saúde em Paulínia, São Paulo.

\section{METODOLOGIA}

No contexto da pesquisa qualitativa trabalhou-se com o referencial metodológico clínico-qualitativo. Esta modalidade corresponde ao estudo teórico de um conjunto de métodos científicos, técnicas e procedimentos, adequados para descrever e interpretar os sentidos e significados dados aos fenômenos relacionados à vida do indivíduo, seja de um paciente ou de qualquer outra pessoa participante do setting dos cuidados com a saúde (equipe de profissionais, familiares, comunidade $)^{(11)}$.

O cenário do estudo foi uma Unidade Básica de Saúde do Município de Paulínia, interior de São Paulo, que possui Ambulatório de Feridas. A coleta das informações deu-se no período de fevereiro a março de 2010 com usuários do serviço. Foram elegíveis usuários em tratamento de FCMI há pelo menos 12 meses; a amostra foi composta mediante o critério de saturação.

Para a coleta das informações foi empregada a entrevista individual semiestruturada, realizadas na Unidade Básica de Saúde, após as consultas médicas semanais. Utilizou-se um roteiro que partia de questões para caracterização do perfil socioeconômico dos entrevistados e, em seguida, era solicitado que explicassem, a partir de seus pontos de vista, como apareceu a FCMI, suas possíveis causas, as formas particulares de cuidado da ferida e como estava a vida após o aparecimento da ferida.

As entrevistas foram registradas em áudio e posteriormente transcritas na íntegra adotando-se nomes fictícios para os informantes. A análise das informações foi realizada mediante a técnica de Análise de Conteúdo ${ }^{(12)}$.

O projeto foi aprovado pelo Comitê de Ética em Pesquisa da Faculdade de Ciências Médicas da Universidade Estadual de Campinas sob protocolo n. 011/2010. Foram respeitados os preceitos éticos da participação voluntária e consentida, segundo a Resolução 196/96, do Conselho Nacional de Saúde e da Resolução 251/97, da Comissão Nacional de Ética em Pesquisa, que regulamentam investigações envolvendo seres humanos; a instituição foi comunicada e esclarecida quanto à viabilidade do estudo e do compromisso de manter o anonimato, tendo autorizado o acesso aos usuários do serviço.

\section{RESULTADOS}

\section{Características de identificação}

Participaram da pesquisa 8 usuários do serviço de saúde, sendo cinco do sexo feminino e três do sexo masculino; a faixa etária variou entre 41 e 50 anos de idade. No que diz respeito à escolaridade, metade dos usuários cursaram o ensino médio completo. Encontramos seis atores sociais com renda familiar de um a dois salários mínimos; a religião referida predominante foi a católica, seguida dos que se identificam como evangélicos e daqueles que referiram não possuir uma religião definida, mas não se consideravam ateus.

As atividades profissionais dos informantes foram divididas em "antes" e "depois" da FCMI, considerando o surgimento da ferida como um possível evento de ruptura biográfica. Neste sentido, pode-se observar o impacto da FCMI na dinâmica trabalhista dos indivíduos adoecidos. Do universo de 8 informantes, cinco encontravam-se afastados de suas atividades laborais em decorrência da ferida.

"Não vejo a hora de sarar para trabalhar!": impacto da ferida na vida cotidiana

As doenças crônicas tendem a assumir uma complexidade que se projeta no cotidiano de vida dos indivíduos adoecidos e de seus familiares. Tal fato ficou evidente nos resultados deste estudo, destacando-se os impactos nas atividades diárias, principalmente as que dizem respeito aos afazeres domésticos e às atividades profissionais dos informantes.

Não vejo a hora de sarar para trabalhar! Tive que parar de trabalhar por causa da ferida [...]. Minha vida praticamente parou! (Zélia)

Você trabalha a vida inteira! Tem duas crianças que precisam ser criadas. E você está amarrada! E não pode fazer mais nada! (Lílian)

Não consigo fazer os serviços de casa! Fico quieta! Minha filha, quando chega do trabalho, é quem faz. (Maria Noêmia)

Dói muito a ferida, dia e noite, mesmo tomando Tylex! O médico disse que, enquanto não fechar, é assim mesmo! Eu queria voltar a trabalhar! Tanta coisa para fazer e eu me sinto inútil, porque sempre trabalhei 
pra fora, agora tenho que ficar deitada e preciso dos outros para fazer uma coisa e outra. Essa doença me deixou muito crica. Vejo-me impotente e sem poder trabalhar. (Zélia)

"O povo vai me ensinando as coisas e eu faço!": práticas de cuidado com a ferida crônica

Os discursos evidenciam a existência de um pluralismo na eleição de métodos terapêuticos para o tratamento da FCMI. Nos depoimentos abaixo pode-se observar uma miscelânia de práticas de cuidado entre os informantes da pesquisa, as quais envolvem saberes e terapêuticas dos variados sistemas de cuidado disponíveis nas sociedades complexas.

A única coisa que eu faço é lavar com folha de mandioca! Dizem que é bom pra coceira. A ferida coça muito! Também disseram que folha de caju é bom! (Maria Inês)

Ah, eu estou seguindo uma religião. Lá recebi uma toalhinha que coloco na perna, em cima da ferida! Está me ajudando bastante! O povo vai me ensinando as coisas e eu faço! Deu uma boa melhorada com o chá, também! (Almerinda)

Agora estou usando uma placa, por indicação médica! [...]. Agora quem vai cuidar da ferida é o médico. Eu durmo descoberto por causa da ventilação, eu acho que o frio da noite é bom para minha cicatrização! (José Eduardo)

\section{"É o nervoso!": um modelo explicativo}

O estado "nervoso" é relatado pelos informantes como um fator que se relaciona com o processo de cicatrização da FCMI. Neste sentido, esta condição físico-moral tende a prejudicar, ou retardar, o tratamento da ferida.

A ferida é assim mesmo [...]. Agora que começou a doer, eu fico nervosa e ai piora. (Maria Inês)

Um dia uma médica falou pra mim: 'eu vou deixar a senhora aqui no hospital. Não que a senhora esteja doente. É por causa da crise nervosa'. Ela falou para eu rir e ir mais devagar: pegar um filme, programa de comédia, conversar. Mas é difícil eu conversar com alguém! (Lílian)
Tem hora que dá um nervoso grande, as coisas que eu fazia: caminhava, ajudava as pessoas. Agora não posso! Tenho que pedir ajuda. Então pra mim é uma coisa muito chata! (Carlos)

A vida mudou psicológica e financeiramente [...]. Hoje ganho $R \$ 510,00$ e ganhava de $R \$ 1.500,00$ a $R \$$ 2.000,00 de salário, mais hora extra e caixinha. Às vezes eu tomo um antidepressivo por um mês e depois paro! (Domingos)

\section{DISCUSSÃO}

O impacto da FCMI nas atividades laborais dos participantes deste estudo vem ao encontro de estudo realizado no interior de Minas Gerais que demonstrou que a maioria dos indivíduos adoecidos estava afastada ou aposentada devido à doença. Além disso, que o tempo médio dessas feridas era de 10 anos e, que apesar das dificuldades de deambular, o usuário geralmente era responsável pelo serviço doméstico, o que poderia interferir no repouso e, consequentemente, no processo de cicatrização ${ }^{(13)}$.

O perfil dos informantes da presente pesquisa reitera as dificuldades apontadas na literatura ${ }^{(13)}$, principalmente no que tange às limitações ao trabalho e à realização de atividades da vida diária, impostas pela FCMI.

A FCMI impõe renegociações perenes das ações e projetos de vida dos indivíduos adoecidos, necessárias para conviver com a doença crônica e apesar dela. Os informantes destacam aquelas ligadas às atividades da vida diária e ao mundo do trabalho.

Os impactos produzidos pela ferida crônica são principalmente relatados pelas mulheres. Fica configurado em suas falas o papel ativo que desenvolviam no sistema cultural da família e, em alguns casos, no mercado de trabalho (sempre trabalhei pra fora). Estas mulheres vêem-se impossibilitadas de seguir desempenhando tais papéis sociais em decorrência da FCMI. Tais limitações são expressas por meio de colocações : "a vida praticamente parou", "você está amarrada", "não pode fazer mais nada", "fico quieta", "eu me sinto inútil", "vejo-me impotente". O impacto da ferida reflete-se na redução das atividades dos indivíduos, anteriormente ativos, em relação ao seu trabalho e tarefas cotidianas. Com a FCMI eles têm que repousar alguns períodos do dia e, por não estarem habituados, sentem-se incomodados com essa situação, a qual é percebida como limitação e incapacidade, além de 
prejuízo econômico: "não vejo a hora de sarar para trabalhar!"

A literatura antropológica tem proposto alguns modelos etiológicos, explicativos e terapêuticos, para a interpretação das respostas de indivíduos ou grupos sociais ao processo saúde-doença. Por meio desses modelos podemos ter acesso ao universo de representações e significados construídos socialmente pelos sujeitos adoecidos $^{(14)}$.

É consenso, nos estudos antropológicos sobre saúde e doença, que entre as classes trabalhadoras a doença tende a ser percebida, interpretada e tratada somente quando há uma incapacitação da performance social, representada principalmente pelo trabalho. Para essa população, estar doente significa um evento altamente incapacitador. Deste modo, a doença não é considerada um evento exclusivamente biológico e se projeta no efeito mais dramático que produz, qual seja, a incapacidade de trabalhar e a consequente ameaça à subsistência familiar ${ }^{(15)}$.

Logo, observa-se no usuário, a importância atribuída ao trabalho, as frustrações e os esforços para manter a rotina diária como a anterior à ferida. Entendemos que a qualidade de vida dos informantes também é afetada já que eles precisam modificar hábitos, com interferência no conforto e bem-estar individual e familiar. Além disso, a ferida prejudica o estado de humor dos atores sociais, deixando-os "crica", ou seja, irritados ou sem paciência. Neste contexto, destaca-se o papel da família e das redes sociais dos adoecidos no processo de enfrentamento do processo saúde-doença.

Os atores sociais, quando apresentam algum tipo de limitação física decorrente da doença crônica ou incapacitante, deixam de exercer suas atividades de modo regular e dependem de terceiros; sua percepção acerca da doença fica clara e evidente, dando início a mudanças estruturais na vida deles ${ }^{(15)}$. Este fenômeno é denominado de ajustamento na enfermidade crônica. Refere-se ao que é feito pela pessoa frente à doença, incluindo a mobilização de recursos, manejos para amenizar os seus efeitos e a mobilização de recursos do contexto cultural ${ }^{(16)}$.

Entre essas mudanças estruturais na vida do indivíduo cronicamente adoecido encontram-se as práticas de cuidados com as quais terá de lidar diariamente. Estas práticas são forjadas por meio das interações com diversas instituições e agentes de cura inseridos na dimensão social e cultural. Os cuidados e terapias populares que são utilizadas como prática de cuidado com a FCMI são diversos. Neste estudo emergiu a coexistência das práticas de cuidados que envolvem a pluralidade de sistemas terapeuticos disponíveis culturalmente nas sociedades complexas.

Os sistemas de cuidado à saúde foram classificados em três grupos ${ }^{(9)}$ : sistema informal ("o povo vai me ensinando as coisa e eu faço"), sistema popular ou tradicional ("a única coisa que eu faço é lavar com folha de mandioca", "deu uma boa melhorada com o chá", "recebi uma toalhinha que coloco na perna, em cima da ferida! Está me ajudando bastante") e o sistema profissional ("agora estou usando uma placa, por indicação médica", "agora quem vai cuidar da ferida é ele"- o médico).

A coexistência desses setores de assistência à saúde coloca à disposição dos indivíduos um repertório variado de informações e práticas que lhes possibilitam reconhecer, interpretar, diagnosticar e tratar os problemas de saúde. Tal fato é demonstrado na fala dos informantes ao apontarem o uso concomitante de terapêuticas populares, envolvendo o uso de plantas medicinais, chás, artigos religiosos e, paralelamente, a frequência às consultas médicas e a utilização de medicamentos.

Um dos informantes inferiu, ainda que discretamente, elementos que compõem a representação da Síndrome do Quente e Fresco: "Eu acho que o frio da noite é bom para minha cicatrização!". Tal síndrome é característica entre os povos latino-americanos, dentre eles os brasileiros ${ }^{(17)}$. Neste sentido, a crença de que o "frio da noite" faz bem ao processo de cicatrização da FCMI ratifica os estudos antropológicos sobre esta temática. Cumpre destacar que não houve aprofundamento sobre esta questão neste estudo, o que se caracteriza como uma limitação do mesmo.

Os resultados do presente estudo corroboram ainda os processos de reinterpretação e validação realizado por usuários de serviços de saúde diante das prescrições de cuidado que os desvinculam de suas redes sociais e culturais, em um cenário que, geralmente, lhes é estranho (o consultório), e que tendem a tomar sua experiência individual baseando-se em parâmetros universais ${ }^{(10)}$. Com isso, os sujeitos sociais reconstroem os modelos explicativos da saúde e da doença de inspiração biomédica, acrescentando-lhes diversos elementos de suas dimensões sociais e culturais. Entre estes modelos não há antagonismos, o que há é dispersão, coexistência, heterogeneidade, repartição, jogos de inclusão/exclusão, transformação, revezamento, posição, substituição.

Os modelos explicativos referentes à ferida crônica 
tangem desde supertições populares, passando por associações ao estado psicológico, especialmente ao nervoso, tema já consagrado na Antropologia Médica brasileira e, por fim, pela obviedade de um acidente.

As explicações dos informantes sobre a experiência de viver com a FCMI elegem o nervosismo e as crises nervosas como categorias fulcrais à construção sociocultural de significados relativos ao curso terapêutico da ferida. Dessa forma, os discursos manifestam um sentido de integralidade na maneira de explicar e compreender o processo de adoecimento, contrapondo-se à unidimensionalidade biológica e mecanicista do modelo biomédico. Para os indivíduos entrevistados, o nervosismo desencadeado pelos impactos da FCMI na vida cotidiana, pelos desconfortos físicos e, principalmente, pela impossibilidade de trabalhar, pode piorar a cicatrização da ferida. No entanto, eles se vêem diante de um imperativo: acostumar-se com essas crises nervosas, pois "a ferida é assim mesmo". $\mathrm{O}$ estado nervoso é relatado como um fator que se relaciona com o processo de cicatrização da FCMI e, neste sentido, o estado emocional tende a prejudicar ou retardar o tratamento da ferida.

Nervos é um conjunto variado e instável de sintomas psicológicos e/ou somáticos, mediadores entre o sujeito sofredor e o seu meio, constituindo uma das expressões de distresse ou estresse social ${ }^{(18)}$. Essa sintomatologia polimorfa e imprevisível pode comprometer as funções orgânicas, inclusive as mentais, indo desde a ansiedade, ou mal-estar indefinido, até crises convulsivas, à catatonia ou à catalepsia, passando por formas variadas de agressividade ou apatia ${ }^{(19)}$.

O nervoso expressa-se sob dois modos diferentes: estar nervoso e ser nervoso. O primeiro diz respeito a um estado de perturbação leve ou passageira, prioritariamente a uma causalidade externa. $\mathrm{O}$ segundo qualifica um estado mais intenso e permanente em que a ênfase recai não no acicate exterior, mas no modo e qualidade interior da perturbação. O ser nervoso divide-se em duas categorias doente dos nervos $e$ temperamento nervoso ${ }^{(20)}$.

Neste estudo, a crise nervosa e o nervosismo não são considerados uma doença (disease) com manifestações clínicas, externas ou infecciosas que alteram as funções físicas. Trata-se, pois, de uma illness produzida pela experiência com a desestabilização da performance social e de condutas morais dos informantes devido aos impactos da FCMI na vida cotidiana.

Em estudo realizado junto a mulheres nervosas de uma colônia de pescadores de Florianópolis, Santa
Catarina, identificaram-se algumas causas para o aparecimento do problema dos nervos. As mais citadas foram: hereditariedade, problemas relacionados aos ciclos femininos, fraqueza constitucional, deficiências alimentares, excesso de problemas materiais ou afetivos, susto, inveja, causas transcendentais ou religiosas, excesso de trabalho físico ou mental, fraqueza moral e, finalmente, "falta de homem" (de relações sexuais) e, ainda, contágio, em outro caso ${ }^{(19)}$. No caso específico dos informantes do presente estudo, o principal elemento desencadeador da crise nervosa foi a ferida. As FCMI caracterizaram-se pelo desconforto físico, dor, sensação de calor e/ou frio, além das complicações decorrentes de processos infecciosos. Além disso, o impacto da FCMI na vida cotidiana dos adoecidos é um importante estressor, também relatado como causador de estados de nervosismo.

O nervosismo associa-se a toda sorte de preocupações e frustrações, que envolvem tanto situações particulares da vida restritas à família, como situações gerais de origem social. Entre as questões sociais, a instabilidade econômica ocasionada pelo adoecimento foi bastante mencionada.

Diante dessa conjunção de causas para o aparecimento do problema dos nervos, as práticas de cuidado referidas são diversas e articulam prescrições socioafetivas, como "rir e ir mais devagar", o que sugere desacelerar o ritmo ou estilo de vida; e prescrições médicas, como "tomar antidepressivo por um mês" e depois parar.

Os estudos antropológicos sobre nervos, no Brasil, têm enfatizado que o principal grupo afetado por esta condição físico-moral são as mulheres ${ }^{(19-20)}$. Sobretudo por serem elas as mais envolvidas no cotidiano familiar, além das questões de ordem pessoal. Cumpre destacar que os informantes do sexo masculino também relataram a experiência do nervosismo. O homem tende a reconhecer uma doença somente em situações drásticas. Quando isso ocorre, com poucas exceções, ele tende a ficar abalado psicologicamente, provavelmente porque o seu reconhecimento como doente significa uma ameaça ao seu papel de provedor familiar, além de obrigá-lo a permanecer no lar durante o dia. Ou seja, num ambiente controlado pelas mulheres em que ele se considera um estranho ${ }^{(15)}$.

Com isso, para os informantes, a condição de estar nervoso (estado efêmero produzido pela FCMI, não caracteriza doença) ou de ser nervoso (estado permanente, caracteriza doença) são experiências distintas, configurando-se como um modelo explicativo possível 
para a melhora ou piora do processo de cicatrização da ferida.

\section{CONSIDERAÇÕES FINAIS}

Este estudo contribuiu para interpretar representações, práticas de cuidado, bem como os impactos e modelos explicativos para a vivência com a FCMI. Pode-se considerar que os diversos problemas de saúde que se tornam visíveis na materialidade do corpo físico são, igualmente, permeados por questões simbólicas que se inscrevem no plano da vida cotidiana dos portadores de ferida, reafirmando o caráter social do processo saúde-doença.

Ao distanciar-se do olhar unicamente biomédico foi possível elencar as principais consequências da FCMI na vida cotidiana dos adoecidos. Entre elas, destacamse as dificuldades para a realização de atividades básicas da vida diária e, sobretudo, a incapacidade que inviabiliza a inserção/manutenção no mundo do trabalho.

Destaca-se a composição de um itinerário terapêutico pautado no pluralismo da assistência à saúde, como reflexo da complexidade da realidade social na qual os usuários do serviço estão inseridos. Com isso, eles reinterpretam as práticas médicas oficiais em articulação com as crenças e práticas sobre a saúde e a doença vigentes em seu contexto cultural.

Os resultados do estudo contribuem para a ampliação do olhar dos profissionais de saúde sobre os adoecidos por FCMI. Sendo assim, a articulação das categorias discutidas aqui pode fornecer uma moldura teórica que possibilite compreender o processo de adoecimento desses sujeitos sociais. Isto porque, os impactos na vida cotidiana gerados pela ferida, os esforços exigidos na construção de itinerários terapêuticos e a busca de tratamento e cura configuram-se, em última instância, como importantes fatores de estresse individual e familiar, podendo culminar no nervoso, referido por participantes deste estudo.

Portanto, os significados que a FCMI assume para os indivíduos portadores são diversos e construídos cotidianamente na teia de significados simbólicos de seu meio cultural mais amplo. Neste sentido, cabe aos profissionais de saúde buscar interpretar as entrelinhas e o não-dito nas queixas, às vezes repetitivas, dos usuários, como forma de promover encontros de cuidados culturalmente congruentes e sensíveis às vivências objetivas e subjetivas do processo saúde-doença.

\section{REFERÊNCIAS}

1. Meetoo D. Chronic diseases: the silent global epidemic. Br J Nurs. 2008;17(21):1320-5.

2. Abbade LPF, Lastória S. Abordagem de pacientes com úlcera da perna de etiologia venosa. An Bras Dermatol. 2006;81(6):509-22.

3. Kreutz I, Meregui MAB, Gualda DMR. Cuidado popular com feridas: representações e práticas na comunidade de São Gonçalo, Mato Grosso, Brasil. Cienc Enferm. 2003;9(1):39-53.

4. Jacondino CB, Severo DF, Rodrigues KR, Lima L, Einhardt RR, Amestoy SC. Educação em serviço: qualificação da equipe de enfermagem para o tratamento de feridas. Cogitare Enferm. 2010;15(2):314-8.

5. Langdon EJ, Wiik FB. Antropologia, saúde e doença: uma introdução ao conceito de cultura aplicado às ciências da saúde. Rev Latino-Am Enfermagem. [Internet] 2010;18(3) [acesso em 23 jan 2011]. Disponível: http://www.scielo.br/pdf/rlae/v18n3/pt_23.pdf

6. Queiroz MS. Saúde e doença: um enfoque antropológico. Bauru: EDUSC; 2003.

7. Magalhães ZR, Matos E, Gonçalves JR, Moreira LC, Gonçalves L, Espinoza LM, et al. Algumas considerações acerca do processo de viver humano de técnicos(as) de enfermagem recém-admitidos(as) em um hospital-escola. Texto \& Contexto Enferm. 2006;15(n.esp):39-47.

8. Helman CG. Cultura, saúde e doença. $4^{\mathrm{a}}$ ed. Porto Alegre: Artmed; 2003.

9. Kleinman A. The illness narratives: suffering, healing, and the human condition. Cambridge: Basic Books; 1988.

10. Melo LP, Cabral ER, Santos Júnior JA. The healthdisease process: a reflection based on medical anthropology. Rev Enfermagem UFPE On Line. 2009;3(4):426-32.

11. Turato ER. Introdução à metodologia da pesquisa clínico-qualitativa: definição e principais características. Rev Port Psicossomática. 2000;2(1):93-108.

12. Campos CJG, Turato ER. Content analysis in studies using the clinical-qualitative method: application and perspectives. Rev Latino-Am Enfermagem. 2009;17(2):259-64. 
13. Martins DA, Souza AM. O perfil dos clientes portadores de úlcera varicosa cadastrados em programas de saúde pública. Cogitare Enferm. 2007;12(3):353-7.

14. Laplantine F. Antropologia da doença. $3^{\mathrm{a}}$ ed. São Paulo: Martins Fontes; 2004.

15. Queiroz MS. Representações sobre saúde e doença: agentes de cura e pacientes no contexto do SUDS. Campinas: Editora da Unicamp; 1991.

16. Canesqui AM, organizador. Estudos antropológicos sobre os adoecidos crônicos. São Paulo: HUCITEC/ FAPESP; 2007. Olhares socioantropológicos sobre os adoecidos crônicos. p. 19-51.

17. Queiroz MS. Hot and cold classification in traditional Iguape Medicine. Ethnology. 1984;23(1):63-72.

18. Guarnaccia P, Cancela V, Carrillo E. The multiples meanings of ataque de nervios in the latino community. Med Anthropol. 1989;11(1):47-62.

19. Silveira ML. O nervo cala, o nervo fala: a linguagem da doença. Rio de Janeiro: Fiocruz; 2000.

20. Duarte LFD. Da vida nervosa nas classes trabalhadoras urbanas. Petrópolis: Vozes; 1986. 